\title{
Failure of Early Recognition of Skeletal Tuberculosis
}

\author{
GEOFFREY F. WALKER,* M.B., F.R.C.S.
}

Brit. med. F., 1968, 1, 682-683

Skeletal tuberculosis, once common in the United Kingdom, is now rare and may be overlooked as a cause of orthopaedic and neurological symptoms. This is illustrated by a study of the tuberculous patients admitted during a single year to the Royal National Orthopaedic Hospital, Stanmore, and five others treated elsewhere in whom the possibility of tuberculosis was not at first considered.

\section{Present Investigation}

During 196234 patients were admitted to the Royal National Orthopaedic Hospital with proved skeletal tuberculosis, of whom 13 had new manifestations of the disease rather than reactivation of a previously recognized lesion. These 13 patients with the five already mentioned are reported in this paper, and 9 of the 18 (8 male, 10 female) were at first misdiagnosed. Their ages ranged from 22 to 75 years, except for one Indian child of 10 . Nine were English, six Indian, two Irish, and one Spanish. Five, possibly six, had evidence of a previous tuberculous lesion in another site.

Details of the lesions are given in Table $\mathrm{I}$; six were in the spine, two each in the hip and the ankle, and one each in the knee, shoulder, elbow, coracoid, first metacarpophalangeal joint, metacarpal, greater trochanter, and ischial bursa. The presenting symptom in 16 was local pain, though one patient complained of sciatica as well as back pain. The exceptions were

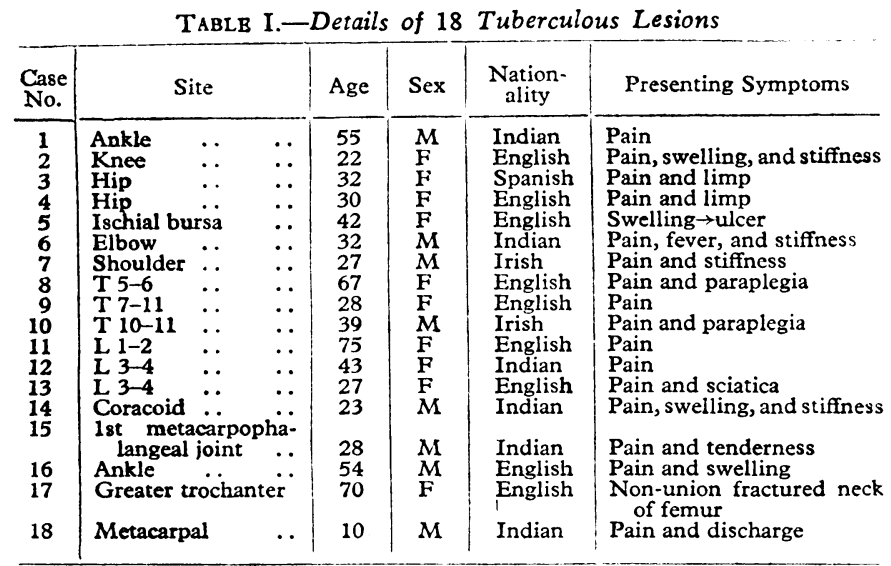

a tuberculous ischial bursa which started as a sacral swelling and then ulcerated, and a lesion of the greater trochanter which caused non-union of a low femoral neck fracture. Two of the spinal lesions produced symptoms of paraplegia, while patients with lesions in the knee, coracoid, elbow, and shoulder also complained of stiffness. Only one patient had noticed fever, and general debility was not mentioned. The two painful hips caused limping.

High-quality radiography is of vital importance in the diagnosis of tuberculous skeletal lesions. In spite of good films the correct diagnosis was not at first suspected in 9 of the 18 patients under consideration (Table II). Two of the spinal lesions were thought to be due to intervertebral disc disorders;

* Queen Mary's Hospital for Children, Carshalton, Surrey, and Epsom District Hospital one ankle case presented as an acute cellulitis, the other as an old injury or neuropathic joint ; one hip case was treated for osteoarthritis for four years. An infected first metacarpophalangeal joint had been regarded as a chronic sprain, and a lesion of the coracoid as an axillary abscess. For eight months a lesion of T 10-11 was regarded as simple backache until paraplegia developed, though definite changes were demonstrable in lateral radiographs. A further five weeks elapsed before the correct diagnosis was made and the patient transferred for onthopaedic attention.

\section{TABle II.-Initial Diagnosis of Nine Lesions Ultimately Proved to be

$\begin{array}{crc}\text { Case } & 1 & \ldots \\ , & 4 & \ldots \\ , & 10 & \ldots \\ , & 12 & \ldots \\ , & 13 & \ldots \\ , & 14 & \ldots \\ , & 15 & \ldots \\ , & 16 & \ldots \\ , & 17 & \ldots\end{array}$ Cellulitis of foot Osteoarthritis Backache, until paraplegia developed Prolapsed intervertebral disc Prolapsed intervertebral disc or pyogenic infection Axillary abscess \\ Old injury, neuropathy \\ Non-union fractured neck of femur}

In two other patients the diagnosis was long delayed. A thoracic spinal lesion was not recognized as tuberculous for eight months after pain began, and a labourer had noticed pain and stiffness in his shoulder for 12 years before radiography revealed caries sicca. A history of a previous pleural effusion was then obtained.

The Mantoux reaction was strongly positive in the nine patients on whom it was performed. Conversion from negative to strongly positive occurred once.

The duration between the onset of symptoms, the clinical diagnosis of tuberculosis, and the confirmation of this diagnosis (histological or bacteriological) is given in Table III. The shortest period to confirmation was three months, the longest four years. In the nine lesions at first misdiagnosed the average delay was one year seven months.

\section{Illustrative Cases}

Case 14.-A 23-year-old Indian man presented with a warm, swollen, stiff shoulder associated with an axillary swelling which had slowly progressed for three months. An abscess was incised on two

TABLE III.-Duration of Symptoms to Clinical Diagnosis of Tuberculosis TABLE III.- Duration of

\begin{tabular}{|c|c|c|}
\hline $\begin{array}{l}\text { Case } \\
\text { No. }\end{array}$ & $\begin{array}{l}\text { Clinical } \\
\text { Diagnosis }\end{array}$ & Confirmation \\
\hline $\begin{array}{l}1 \\
2 \\
3 \\
4 \\
5 \\
6 \\
7 \\
8\end{array}$ & $\begin{array}{l}3 \text { months } \\
6 \text { "’ } \\
4 \text { years } \\
7 \text { months } \\
4 \text { "” } \\
3 \text { 12 years } \\
8 \text { months (5 months }\end{array}$ & $\begin{array}{l}4 \text { months (histology) } \\
8 \text { months (guinea-pig inoculation) } \\
4 \text { years (guinea-pig inoculation) } \\
8 \text { months (histology) } \\
4 \text { months (culture) } \\
3 \text { months (histology). } 6 \text { months (culture) } \\
\text { Positive pleural effusion } 12 \text { years previously } \\
11 \text { months (guinea-pig inoculation) }\end{array}$ \\
\hline $\begin{array}{r}9 \\
10\end{array}$ & $\begin{array}{l}\text { paraplegia) } \\
2 \text { years } \\
8 \text { months }\end{array}$ & $\begin{array}{l}2 \text { years (guinea-pig inoculation) } \\
9 \text { months (A.A.F.B. seen). } 11 \text { months (guinea-pig } \\
\text { inoculation) }\end{array}$ \\
\hline 11 & Some months & $\begin{array}{l}\text { (Positive culture from lesion of cervical spine } 3 \\
\text { years previously) }\end{array}$ \\
\hline $\begin{array}{l}12 \\
13 \\
14 \\
15 \\
16\end{array}$ & $\begin{array}{l}4 \text { years } \\
4 \text { months } \\
3 \\
10 " \\
18 \%\end{array}$ & $\begin{array}{l}4 \text { years (histology and culture) } \\
7 \text { months (guinea-pig inoculation) } \\
3 \text { months (histology) } \\
10 \text { months (histology) } \\
18 \text { months (A.A.F.B. seen). } 20 \text { months (guinea-pig } \\
\text { inoculation) }\end{array}$ \\
\hline $\begin{array}{l}17 \\
18\end{array}$ & $\begin{array}{ll}15 & ,\end{array}$ & $\begin{array}{l}15 \text { months (culture) } \\
8 \text { months (histology). } 10 \text { months (culture) }\end{array}$ \\
\hline
\end{tabular}

A.A.F.B. $=$ Acid-alcohol-fast bacilli 
occasions without resolution, and wider exploration revealed a tuberculous coracoid process.

Case 15.-An Indian man aged 28 complained of pain and tenderness in the first metacarpophalangeal joint of his right hand for two months. He had received injections of hydrocortisone and physiotherapy for seven months before there were radiographic changes of sufficient severity to justify biopsy. Unfortunately only the joint capsule was examined, and it was not until three months later that bone removed from the base of the metacarpal was found to contain tuberculous granulation tissue. The earliest $x$-ray changes were of minimal periosteal reaction, which suggested a fracture. Further films showed slow destruction of the cortex with an increase of periosteal new bone.

Case 16.-A 54-year-old Englishman developed increasing pain and swelling of his ankle for one year. As the joint had suffered a minor injury 12 years previously he was treated with physiotherapy, including short-wave diathermy, heat, and exercises for six months, without relief. He presented at a second hospital with a grossly disorganized joint and a fluctuant swelling over the lateral malleolus. The destruction was so severe that neuropathy was considered, but pus aspirated from the swelling contained tubercle bacilli. He had been treated for a pleural effusion 20 years previously.

Case 17.-A 70-year-old Englishwoman whose tuberculous left kidney had been removed 20 years previously slipped and fractured the neck of her femur. This was immobilized with a pin and plate, but union did not occur, and finally the implant was removed with release of copious pus from which tubercule bacilli were cultured. In retrospect it was obvious from the radiographs that the greater trochanter had already disappeared at the time of the fracture.

Case 18.-A 10-year-old Indian boy presented at a London hospital with a sinus which had been discharging on the back of his hand for eight months. There had been little swelling, but pain was severe until the discharge began. A cystic destructive lesion in the second metacarpal involving both epiphysis and metaphysis was shown by radiography. Culture and histology were positive for tuberculosis.

\section{Discussion}

It is a truism to say that to make a diagnosis of tuberculosis one must consider it as a possibility. Tuberculosis has now joined syphilis as a great deceiver largely because its rarity so often excludes it from consideration in differential diagnosis. The arrival of immigrants prone to or suffering from tuberculosis in whom skeletal lesions often present in unusual ways, and the fairly rare but eminently treatable fresh cases arising among the indigenous population, make it vital that the possibility of tuberculosis as a cause of skeletal pain (which may be referred) should always be remembered (Hunt, 1964), particularly as these lesions usually respond satisfactorily to antibiotics reinforced by surgery when indicated.

Good-quality radiographs should be insisted on (repeated later if necessary), together with films of the corresponding normal side for comparison. A positive Mantoux reaction is of value. A raised sedimentation rate, though not specific, must not be ignored. Suspicion of a tuberculous lesion should be confirmed by histology or bacteriology before antibiotic therapy is begun (M. Heywood-Waddington, personal communication, 1964 ; Kirkaldy-Willis and Thomas, 1965), and this usually demands biopsy, which should not be delayed if reasonable suspicion exists.

\section{Summary}

Tuberculous lesions of bones and joints are being overlooked because the possibility of their occurring, often in unusual ways, is not remembered.

Nine of the 18 cases reported were at first misdiagnosed, with an average delay of one year seven months before tuberculosis was confirmed.

Pain was the commonest presenting symptom.

Good-quality radiographs and a positive Mantoux reaction are of value in suggesting the diagnosis.

Histological or bacteriological confirmation is very important and often necessitates biopsy.

I am indebted to the many surgeons who have allowed the inclusion of records of patients under their care in this report ; to Mr. J. A. Cholmeley, who has kindly read the manuscript ; and to the consultant medical staff of the Royal National Orthopaedic Hospital for permission to publish.

\section{REFERENCES}

Hunt, D. D. (1964). F. Amer. med. Ass., 190, 95.

Kirkaldy-Willis, W. H., and Thomas, T. G. (1965). f. roy. Coll. Surg. Edinb., 10, 109.

\section{Medical Memoranda}

\section{Rupture of Sinus of Valsalva}

\section{Brit. med.F., 1968, 1, 683-684}

Congenital aneurysm of the sinus of Valsalva is a rare malformation of the heart. Abbott (1936) collected 12 cases in her series of 1,000 congenital heart diseases; and Sawyers, Adams, and Scott (1957) found 37 cases of rupture of the sinus of Valsalva in the literature.

The object of this paper is to describe the clinical course of such a case, particularly in relation to its diagnosis and management.

\section{Case Report}

The patient, a Chinese woman aged 27, was referred for a medical opınion because of a cardiac murmur. She was gravida-4 and five months pregnant. There was no history of undue dyspnoea on exertion. Her previous pregnancies had been uncomplicated, but a cardiac murmur had been noted during her first pregnancy, seven years ago.

Physical examination showed a moderately nourished woman in good general condition. Pulse rate was 70 per minute and blood pressure 110/60. Jugular venous pressure was not raised and there was no suprasternal pulsation or Corrigan's sign. The apex beat was at the fifth intercostal space on the midclavicular line, and was normal in character. There was no parasternal lift and pulmonary closure was not palpable. No thrills were present. The first heart sound was soft and was followed by a loud harsh pansystolic murmur, which was maximal over the pulmonary area but also heard all over the precordium. Splitting of the second heart sound was not heard. There was no diastolic murmur. Other systems were normal. All the peripheral pulses were palpable and equal.

$X$-ray examination of the chest showed fullness of the right and left cardiac borders, but the heart size and pulmonary artery appeared normal The lung fields were within normal limits. An electrocardiogram showed no evidence of right or left ventricular hypertrophy and there was no bundle-branch block.

The patient received chlorothiazide $500 \mathrm{mg}$. in the morning for five days a week, and was in good condition until two months later, when she was admitted to hospital with a history of small haemo- 